\title{
Study of the microphysical properties associated with the Monsoon Intraseasonal Oscillation as seen from the TRMM observations
}

\author{
M. Halder, P. Mukhopadhyay, and S. Halder \\ Indian Institute of Tropical Meteorology, Dr. Homi Bhabha Road, Pashan, Pune-411008, India \\ Correspondence to: P. Mukhopadhyay (mpartha@tropmet.res.in)
}

Received: 27 October 2011 - Revised: 24 April 2012 - Accepted: 10 May 2012 - Published: 1 June 2012

\begin{abstract}
The spatio-temporal variability of Indian Summer Monsoon is well studied based on different types of rainfall data. However, very few attempts have been made to study the underlying role of clouds and its hydrometeors on Monsoon Intraseasonal Oscillations. The northward propagating Monsoon Intraseasonal Oscillations and its characteristics remain a challenge for the numerical modelers even today. In view of this, we have set out to analyze the role of cloud hydrometeors and their linkage with northward propagating Monsoon Intraseasonal Oscillations. The science question that we intend to address here is whether the different phases of the cloud hydrometeors show similar propagation characteristics as that of rainfall, and what are the relations of their phases with the convection centre using Tropical Rainfall Measuring Mission data. In answering the question, we have analyzed ten years of Tropical Rainfall Measuring Mission 2A12 hydrometeor data over Indian region. Our analyses show that the cloud water and cloud ice do show a large scale organization during the Indian Summer Monsoon regime of June-September, and systematically progress northward getting initiated over equatorial Indian Ocean. On further analyses, we found that cloud water actually leads the rainfall and cloud ice lags the rainfall. We have further demonstrated the process by analyzing dynamical parameters from Modern Era-Retrospective Analysis for Research and Applications. The presence of cloud water in the lower troposphere in the leading edge of rainfall indicates the lower level moistening and preconditioning of the convective instability due to enhanced moisture convergence. Subsequently, deep convection is triggered, which generates hydrometeor above freezing level and cloud ice in the upper troposphere. To quantify objectively the relation among cloud liquid water, cloud ice and rainfall, the lag correlation is computed with respect to convection center, where the above hypothesis is estab-
\end{abstract}

lished that cloud liquid water leads the rainfall and cloud ice lag. This relation among hydrometeors may help the numerical modelers to incorporate such processes for capturing the characteristics of Monsoon Intraseasonal Oscillations.

Keywords. Meteorology and atmospheric dynamics (Convective processes)

\section{Introduction}

The dominant role of intraseasonal variability (ISV) on modulating the tropical climate has been widely studied (Lau and Waliser, 2005; Zhang, 2005). Besides the dominant eastward propagating Madden-Julian-Oscillation (MJO) (Madden and Julian, 1994) during boreal winter, a strong 30-60 day ISV mode propagating north/north-westward dominates the Indian subcontinent during boreal summer (Yasunari, 1979; Hsu and Weng, 2001). The northward propagating ISVs are closely linked with the active/break cycles of Indian Summer Monsoon (ISM) (Sikka and Gadgil, 1980; Lawrence and Webster, 2002) and as such are considered to be the major building block of ISM (Goswami, 2005). Even though substantial research work has been carried out on ISV and its northward propagation, the General Circulation Models have showed limited success in simulating these features of ISM. However, a recent Coupled General Circulation Model (CGCM) study shows some promise (Pattanaik and Kumar, 2010) in capturing at least the seasonal cycle of ISM and the seasonal rainfall but not so much of ISV. So the realistic simulation of ISVs by current climate models still remain a challenge and an open problem (Sperber et al., 2000; Waliser et al., 2003; Chattopadhyay et al., 2009).

The Monsoon Intraseasonal Oscillation (MISO) represents a signal with amplitude as large as the annual cycle and much 
larger than the inter-annual variability of the seasonal mean (Waliser, 2006; Goswami et al., 2006). Due to its quasiperiodic occurrence, the MISO provides a primary source for the predictability of the Asian summer monsoon on subseasonal time scales, and thus has received significant attention. Having a better understanding of this northward propagating subseasonal mode would greatly benefit a wide-range of forecasting applications (e.g. Goswami, 2005).

A number of theories have been put forward in explaining the northward propagation of MISO. Webster (1983) showed the role of land surface heat flux into Planetary Boundary Layer (PBL) to make the atmosphere unstable north of convection centre. Wang and Xie (1997) and Lawrence and Webster (2002) showed that the northward propagation of MISOs is due to the Rossby wave response from the eastward propagating equatorial Kelvin Rossby wave. The role of air-sea interaction is proposed by Kemball-Cook and Wang (2001) and $\mathrm{Fu}$ et al. (2003) for northward propagation. Jiang et al. (2004) gave a theoretical framework to investigate the northward propagating Boreal Summer Intraseasonal Oscillations (BSISO) where they proposed that a combination of vertical wind-shear and moisture convection feedback mechanism is necessary for the northward propagation of the convection. They showed that the northward shift of enhanced low level moisture convergence associated with a positive equivalent barotropic vorticity help in preconditioning the lower atmosphere for the northward propagation of BSISO. Wang et al. (2005) argued that MISOs are originated from equatorial Indian Ocean and are a kind of self-sustaining systems. Hoyos and Webster (2007) argued that mountain ranges need to be resolved well to capture all the characteristics of MISO. Zuluaga et al. (2010) used TRMM 2A12 latent heating $(\mathrm{LH})$ and convective stratiform heating $(\mathrm{CSH})$ products to demonstrate their role and linkage with MISO. In a recent study, Chattopadhyay et al. (2009) hypothesized and subsequently proved the hypothesis using a simple model that the stratiform component of the heating dominantly influences the northward propagation of MISOs.

It is also widely documented that the tropical region is dominated by high clouds (cirrus) (Baker, 1997; Wylie et al., 1994), which are comprised of ice phase. The persisting ice clouds play a major role in the cloud radiative forcing (Baker, 1997). The high clouds made up with ice phase are manifestation of old convection as per Houze Jr. (1997). The anvil part of the deep convection actually is the source of high clouds and the stratiform component of the total rainfall is found to be associated with the region of anvil (Schumacher and Houze Jr., 2003; Johnson, 1984). Divergence in the upper troposphere caused by sub-tropical jet stream can also be responsible for the development of middle and high-altitude clouds in the tropics. In a recent paper L'Ecuyer and McGarragh (2010) mentioned that net Top of the Atmosphere (TOA) radiation imbalances are driven by the absorption of Long wave (LW) radiation by high clouds associated with the deep convection. It is also documented by Bony et al. (2004) and Yuan and Hartmann (2008) that there is a significant correlation between high cloud persistence, their influence on the LW radiation and the large scale vertical motion. The dominance of high clouds over global tropics and its linkage with the stratiform rainfall are also documented. Thus, it is evident from the above discussion that the persistence of high cloud plays a significant role on the radiation budget and they are associated with the region of large scale ascent. In view of the above, it will be worthwhile to explore the role of different hydrometeors namely ice phase, liquid phase and mixed phase, which are actually responsible for the formation of different cloud regimes (high, middle and low). As the ISM, with its variability, is an important component of global climate system this study is particularly intended to understand and document the role of different cloud hydrometeors on the northward propagation of MISO.

This study can eventually become a basis for numerical modelers to include these microphysical processes in numerical models particularly in the General Circulation Model to improve the ice phase process vis-à-vis the stratiform rainfall to possibly improve the northward propagation. Presently, the simulation of seasonal cycle of monsoon and MISOs are not significant (Krishna Kumar et al., 2010). Therefore, the objective of the study is to analyse space time distribution of different hydrometeors, particularly ice phase and mixed phase from TRMM data, and find their role on the northward propagation of MISO.

\section{Methodology}

The Tropical Rainfall Measuring Mission (TRMM) generated products namely $3 \mathrm{~B} 42,3 \mathrm{G} 68$ and $2 \mathrm{~A} 12$ are utilized for the study. The algorithm 3B42 means level 3 merged high quality (HQ)/infrared (IR) precipitation and root-mean-square (RMS) precipitation-error estimates. The combined instrument rain calibration algorithm (3B42) uses a combination of 2B31, 2A12, SSMI (Special Sensor Microwave/Imager), AMSR (Advanced Microwave Scanning Radiometer) and AMSU (Advanced Microwave Sounding Units) precipitation estimates (referred to as High Quality) (further details can be found in http://trmm.gsfc.nasa.gov/ 3b42.html). Near-global estimates are made by calibrating the IR brightness temperatures to the HQ estimates. These gridded estimates are on a 3-h temporal resolution and in a $0.25^{\circ} \times 0.25^{\circ}$ spatial resolution in a global belt extending from $50^{\circ} \mathrm{S}$ to $50^{\circ} \mathrm{N}$ latitude, available for the period (1997present) (Huffman et al., 1995; Huffman, 1997).

The 3B42 daily rainfall dataset is obtained by daily accumulation of rainfall from the 3-hourly data. Using the TRMM 3B42 merged $\left(0.25^{\circ} \times 0.25^{\circ}\right)$ gridded rainfall products and based on a central India $\left(18^{\circ} \mathrm{N}-25^{\circ} \mathrm{N}, 75^{\circ} \mathrm{E}-83^{\circ} \mathrm{E}\right)$ box, a central India precipitation index (CIPI) is prepared as a metric to identify the ISOs. As a first step to compute the CIPI, eleven year (1998 to 2008) daily rainfall smoothed 
TRMM 3B42 JJAS Mean Precipitation( $\mathrm{mm}$ day $\left.^{-1}\right)$ 1998-2008

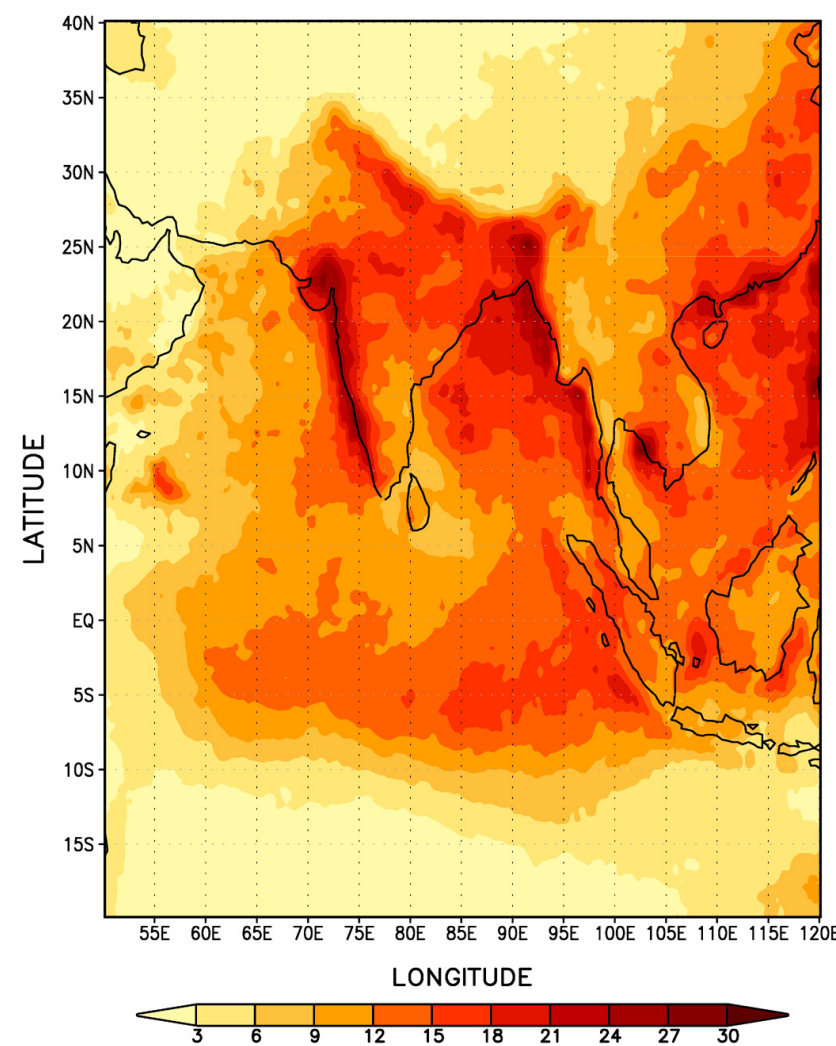

Fig. 1. TRMM 3B42 June-September (JJAS) mean precipitation $\left(\mathrm{mm}\right.$ day $\left.^{-1}\right)$.

climatology (by using the mean and retaining the first three harmonics in the original precipitation time series) for 1 June to 30 September (JJAS) are constructed. Subsequently, a 1090 day filtered (Lanczos type filter following Duchon, 1979) anomaly time series is prepared and the time series is normalized by its own standard deviation.

Those days when the standardized rainfall anomaly exceeds $+1(-1)$ are considered to be active (break) monsoon days. If there are four such consecutive days when the standardized anomaly exceeds +1 , then it is considered to be an active spell. Lag lead composite of the active phases are prepared by fixing the lag 0 as the central day of the established active spells.

TRMM 2A12 data sets (Kummerow et al., 2001) are the TRMM Microwave Imager (TMI) level 2 orbital (15 to 16 passes for a day) Hydrometeor Profile (14 vertical levels) products, which are converted into $0.25^{\circ} \times 0.25^{\circ}$ gridded daily data. TMI is a nine-channel $(10-85 \mathrm{GHz})$ dualpolarized passive microwave radiometric system that measures atmospheric and surface brightness temperature, and compares all nine channels simultaneously to a large set (apriori database) of cloud resolving model profiles. Similar to
Intraseasonal Variability of 3B42 JJAS Rainfall $\mathrm{mm}^{2} \mathrm{day}^{-2}$ (1998-2008)

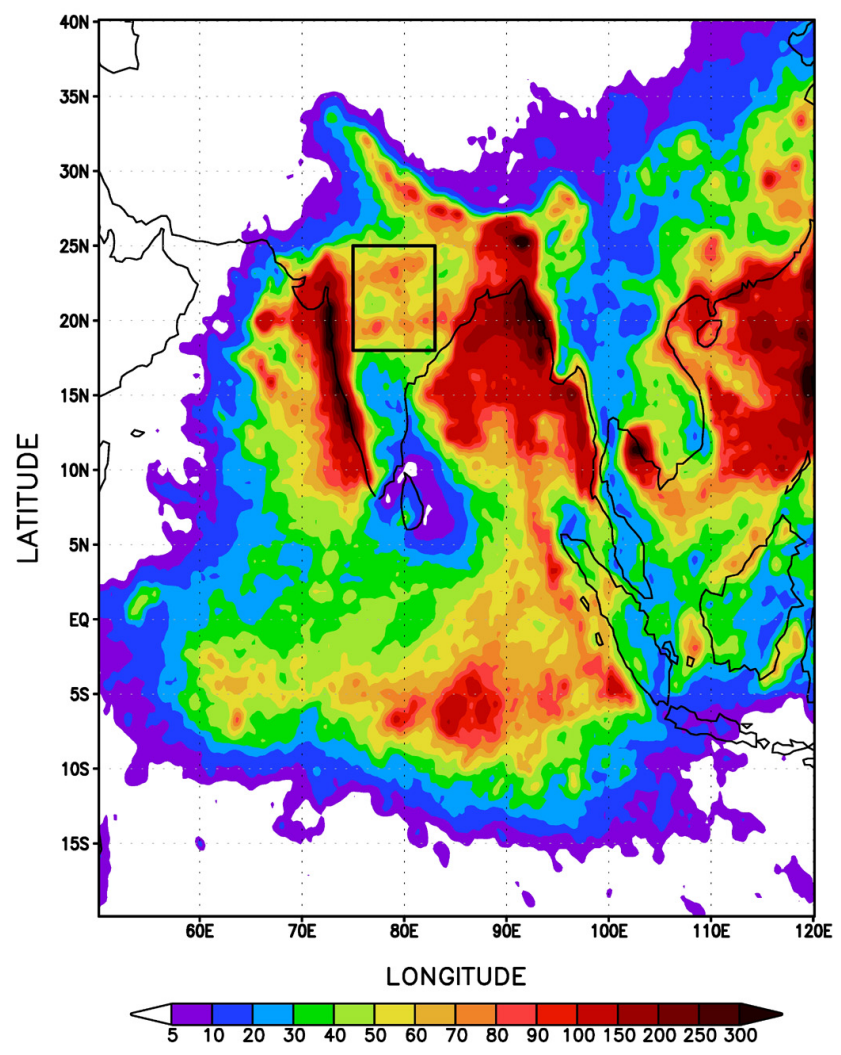

Fig. 2. Intra-seasonal variability of JJAS rainfall $\left(\mathrm{mm}^{2}\right.$ day $\left.{ }^{-2}\right)$ based on 3B42 data.

the above mentioned rainfall analyses, the Cloud Ice, Precipitable Ice and Cloud Water obtained from TRMM 2A12 data for JJAS of 1998 to 2008 are filtered (10-90 days) using a Lanczos filter and using the reference 3B42 rainfall time series over central India, the lag composite of active days are prepared and compared with that of rainfall.

TRMM derived data set referred to as $3 \mathrm{G} 68$, is a combination of TRMM products 2A12, 2A25 and 2B31 (Haddad et al., 1997a, b; Iguchi et al., 2000; Kummerow et al., 2001). For this study the daily data with a resolution of $\left(0.5^{\circ} \times 0.5^{\circ}\right)$ for JJAS from 1998 to 2008 are used. An eleven year time series of convective, stratiform and total rain component has been generated based on Chattopadhyay et al. (2009). The stratiform and convective components of the total rain are specifically used to establish the relation of rainfall with other hydrometeors. 3G68 data is also filtered for 10-90 days using Lanczos filter. The filtered data is used to make the spatial pattern of lag composite of active days rainfall, using TRMM 3B42 rainfall time series over central India as reference time series.

To examine the dynamical and thermodynamical processes associated with observed characteristics of hydrometeors during northward propagation of MISO events, Modern 

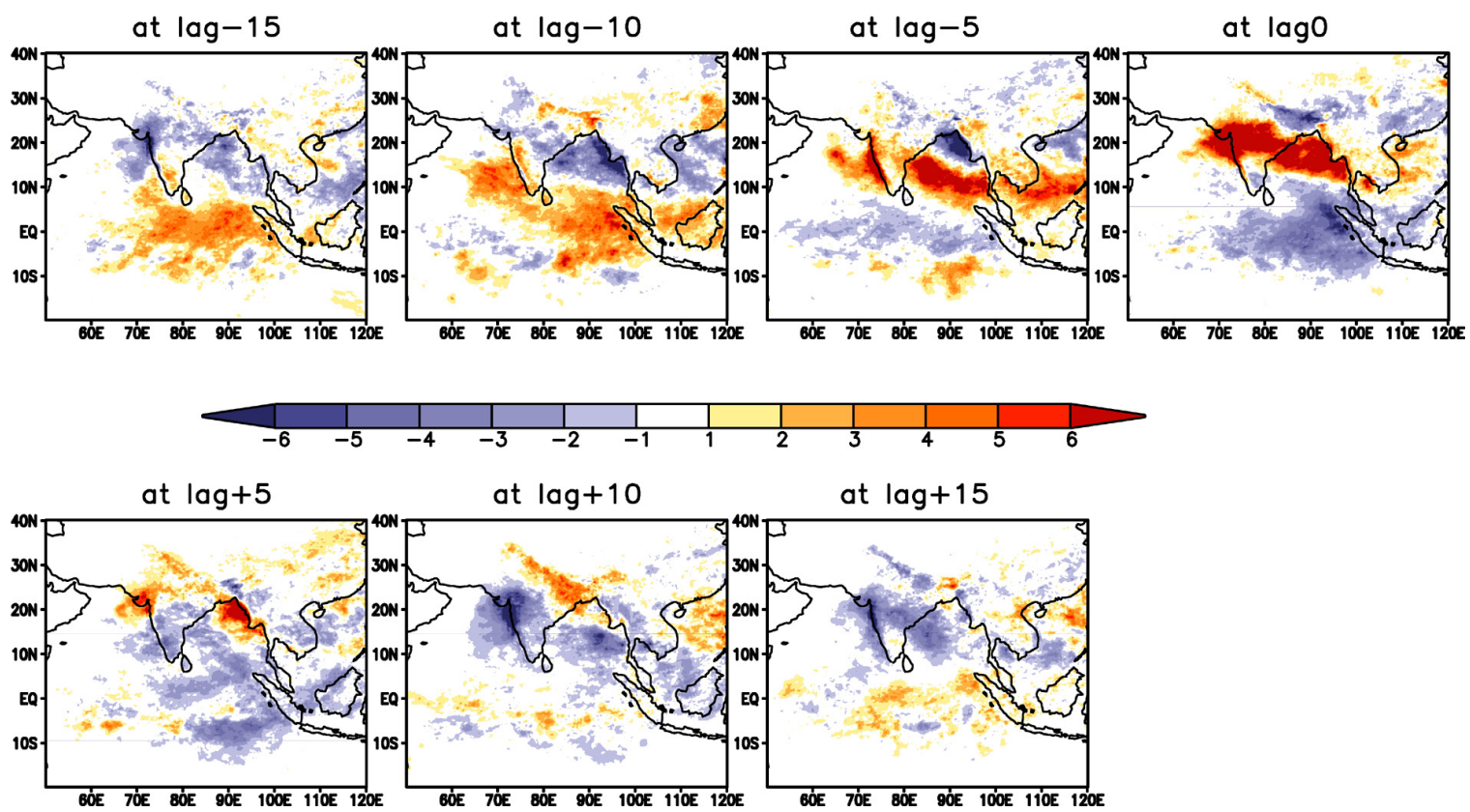

Fig. 3. Lag composite of rainfall $\left(\mathrm{mm}^{-1 a y}{ }^{-1}\right)$ during active spells based on CIPI using TRMM 3B42 data for the period $1998-2008$.
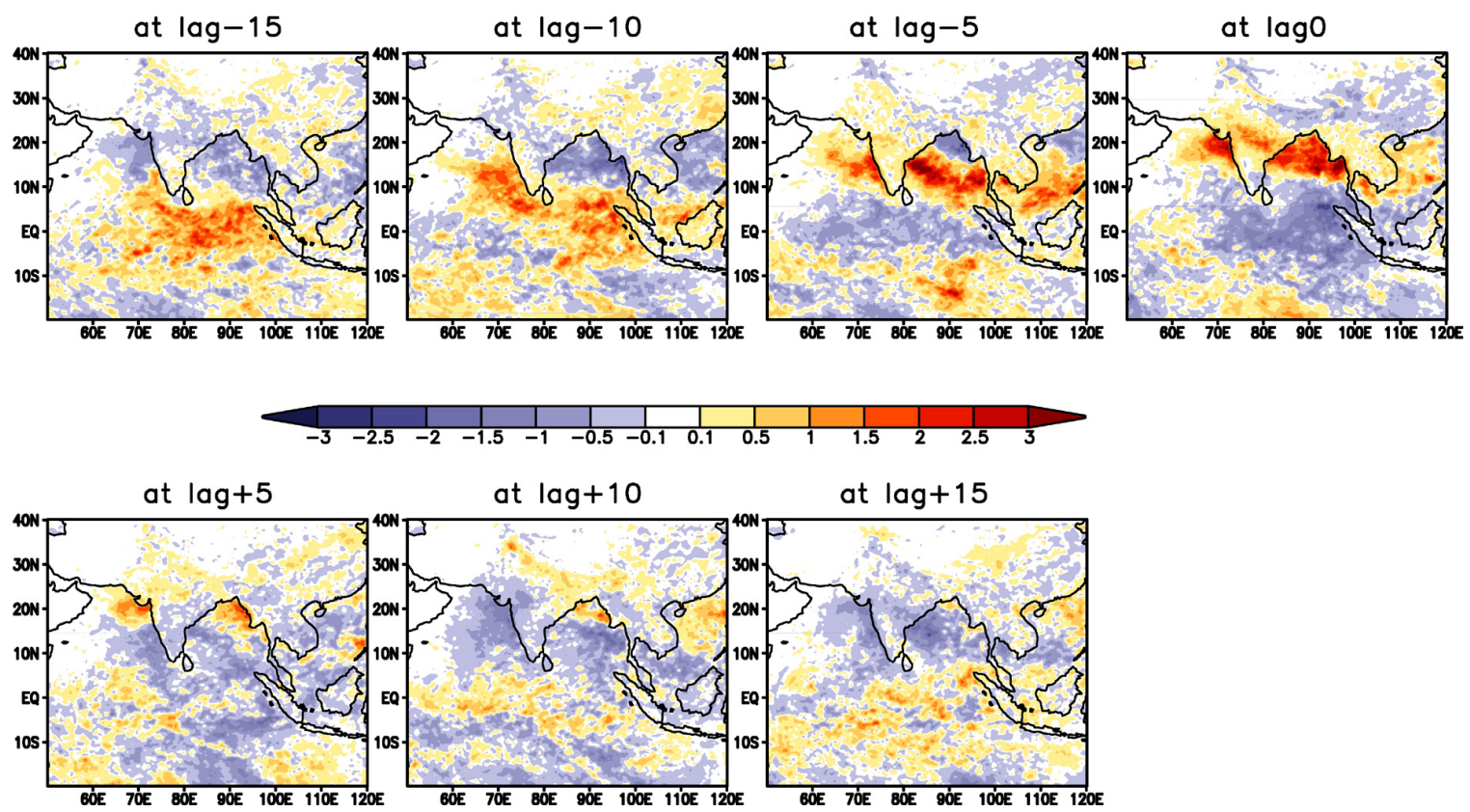

Fig. 4. Lag composite of cloud ice $\left(\mathrm{mg} \mathrm{m}^{-3} \mathrm{day}^{-1}\right)$ during active spells based on CIPI using TRMM 2A12 data for the period $1998-2008$.

Era Retrospective-analysis for Research and Applications (MERRA) is also utilized. MERRA is a National Aeronautics and Space Administration (NASA) atmospheric reanalysis project for the satellite era based on a new version of the Goddard Earth Observing System Data Assimilation System Version 5 (GEOS-5), with the adoption of a joint analysis with the National Centers for Environmental Prediction (NCEP) and of a new set of physics packages for the atmo- spheric general circulation model (AGCM). MERRA focuses on historical analyses of the hydrological cycle on a broad range of weather and climate time scales. MERRA data are available from 1979 through present. For this study, daily $u, v, \omega$, geopotential height, temperature, specific humidity with a horizontal resolution of $1.25^{\circ} \times 1.25^{\circ}$ at 42 pressure levels for JJAS from 1998 to 2008 are used. Detailed 

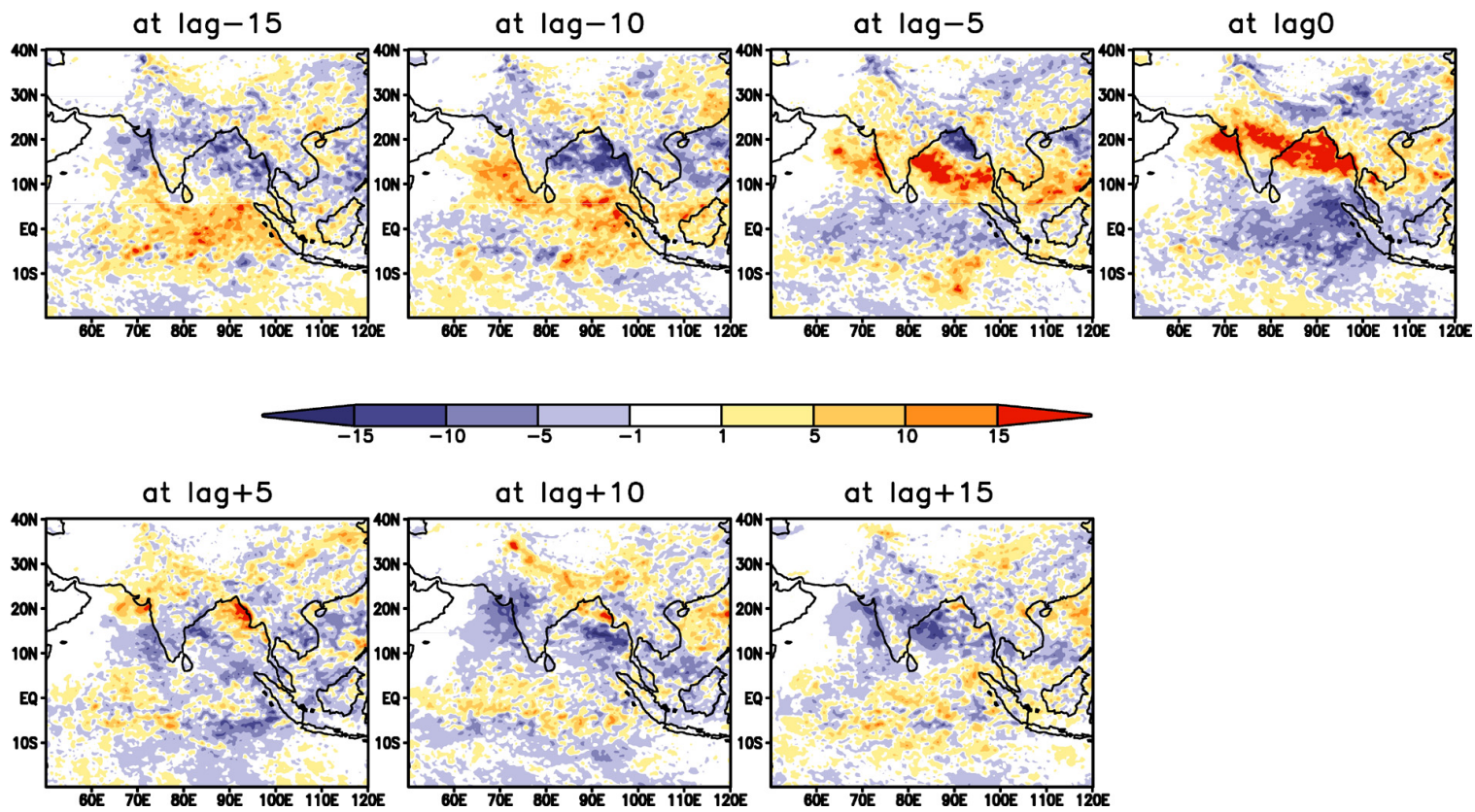

Fig. 5. Lag composite of precipitable ice $\left(\mathrm{mg} \mathrm{m}^{-3} \mathrm{day}^{-1}\right)$ during active spells based on CIPI using TRMM 2A12 data for the period 19982008.
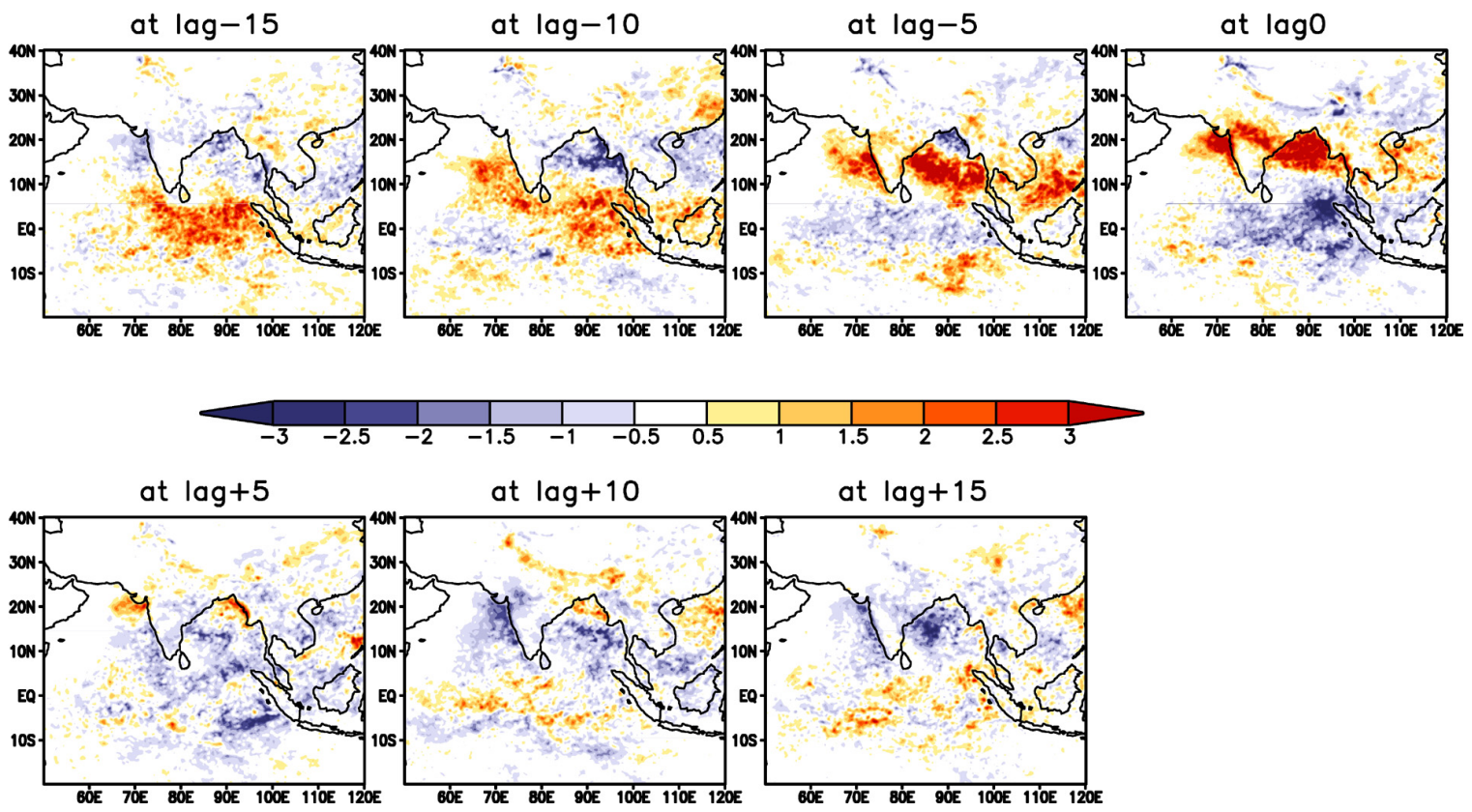

Fig. 6. Lag composite of cloud water $\left(\mathrm{mg} \mathrm{m}^{-3} \mathrm{day}^{-1}\right)$ during active spells based on CIPI using TRMM 2 A12 data for the period 1998-2008.

documentation of the data access and procedures can be found at http://gmao.gsfc.nasa.gov/MERRA.

\section{Discussion of results}

The seasonal mean rainfall for the months of JuneSeptember (JJAS) for 11 years (1998-2008) based on TRMM 3B42 data are shown in Fig. 1. The seasonal rainfall distribution reasonably depicts the higher rainfall zones over Indian sub-continent, namely, the western coast and Bay 
DOMAIN AVERAGED COMPOSITE TIME-SER: HYDROMETEORS VS RAINFALL

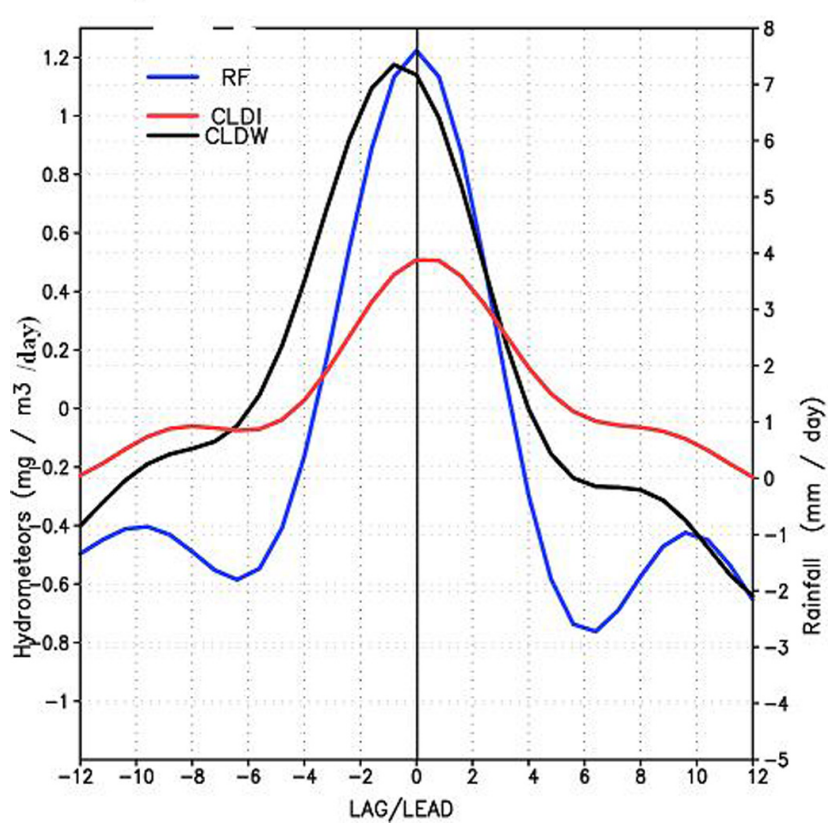

Fig. 7. Domain averaged lag-lead of cloud water $\left(\mathrm{mg} \mathrm{m}^{-3}\right.$ day $\left.^{-1}\right)$ and ice $\left(\mathrm{mg} \mathrm{m}^{-3} \mathrm{day}^{-1}\right)$ with respect to rainfall.

of Bengal region. Further, to get an insight on the intraseasonal signal in the rainfall data, the variance of the intraseasonal rainfall is shown in Fig. 2, where the variability is relatively homogeneous within the mentioned box $\left(18^{\circ} \mathrm{N}-\right.$ $25^{\circ} \mathrm{N}, 75^{\circ} \mathrm{E}-83^{\circ} \mathrm{E}$ ), as compared to those regions near the mountains. Both these figures reasonably bring out the characteristics of the seasonal monsoon rain over the Indian region, showing the region of higher variability and the region of lower variability (central India box). The central Indian plain has lesser spatial heterogeneity. The spatial homogeneity may be manifested in the intraseasonal rainfall variability. The north-south oriented Western Ghat mountains on the west coast of southern India show high mean rainfall and variability mainly due to orographic lifting of moisture laden monsoonal wind. The presence of Western Ghat and landocean contrast might have contributed in the spatial variability of rainfall over the Arabian Sea. The northern Bay of Bengal is the location where the monsoon systems, namely depressions and lows, are formed and as a result the mean rainfall of this region is high. The Myanmar coast is a region of topographic influence, and high variability of rainfall is also noticed over this region. These regional features are one of the factors that decides the rainfall variability over India and adjoining seas. However, Sea surface temperature gradient can also play a role on the rainfall variability over the oceanic region as shown by Shankar et al. (2007).

The prime objective of the paper is to identify the role of hydrometeors on the northward propagation of MISOs, which are major building blocks of the seasonal total rainfall. To start the analyses, we first make a lag composite (Fig. 3) of daily rainfall anomaly from 3B42 data for active days (active days are identified based on CIPI as discussed in earlier section). This will help to show whether the $3 \mathrm{~B} 42$ data has the characteristic large scale organization during active phases, and correspondingly, a lack of large scale organization during break. Northward propagation of positive rainfall anomaly from equatorial Indian Ocean (lag -15) to central Indian latitude (lag +5 days) is clearly visible (Fig. 3 ). The northward propagation of positive rainfall is subsequently followed by a negative rainfall anomaly over the equatorial Indian Ocean. At lag +15 days, the whole Indian subcontinent is covered by a negative rainfall anomaly signifying a break in monsoon rainfall activity. The northward progression of rainfall anomaly at a period of 30 days shows the large scale organization of rainfall at 0 th lag.

Although the northward progression of convection anomalies were showed by many other studies, e.g. Sikka and Gadgil (1980) using outgoing longwave radiation (OLR), rainfall, etc. as metric, however, the northward progression of cloud hydrometeors and their phases have hardly been explored. We now would like to study whether the cloud ice has an intraseasonal periodicity of around 30 days and whether it shows a coherent northward progression as seen in the rainfall data.

To get an insight about the cloud ice derived from TRMM 2A12 data, we take the CIPI based on TRMM 3B42 daily rainfall time series as the reference and make a composite of active spells with -15 to +15 day lag. The cloud ice is considered at a representative level of $10 \mathrm{~km}$, where its concentration is found to be maximum as compared to other levels. We see (Fig. 4) that a positive cloud ice anomaly organizes over the equatorial Indian Ocean region, which then progressively travels northward to reach the Indian land mass at 0 lag. The organization of positive cloud ice anomaly shows a typical large scale alignment from north-west to south-east across the Indian sub-continent. In subsequent days a negative anomaly develops over the equatorial Indian Ocean and starts progressing northward. Thus, the cloud ice also shows a similar positive (negative) anomaly as seen in daily rainfall during an active (break) phase of monsoon with a periodicity of 30 days.

To further investigate the characteristics of northward propagation of the mixed phase hydrometeor, the precipitable ice at $6 \mathrm{~km}$ level is analyzed as a lag composited diagram. The precipitable ice also shows (Fig. 5) northward propagation from lag -15 days to lag 0 days and further to lag +15 days, but with higher amplitude than cloud ice at 0 lag (Fig. 5). The cloud water at $3 \mathrm{~km}$ (Fig. 6) shows a similar northward progression from lag -15 to +15 days as is seen in rainfall.

Thus, it is evident from the above analyses that the hydrometeors, e.g. cloud ice, precipitable ice and cloud water systematically show a northward progression starting from 
98-08 Active Composite meridional-vertical structure of anomalous Temperature \& Specific Humidity
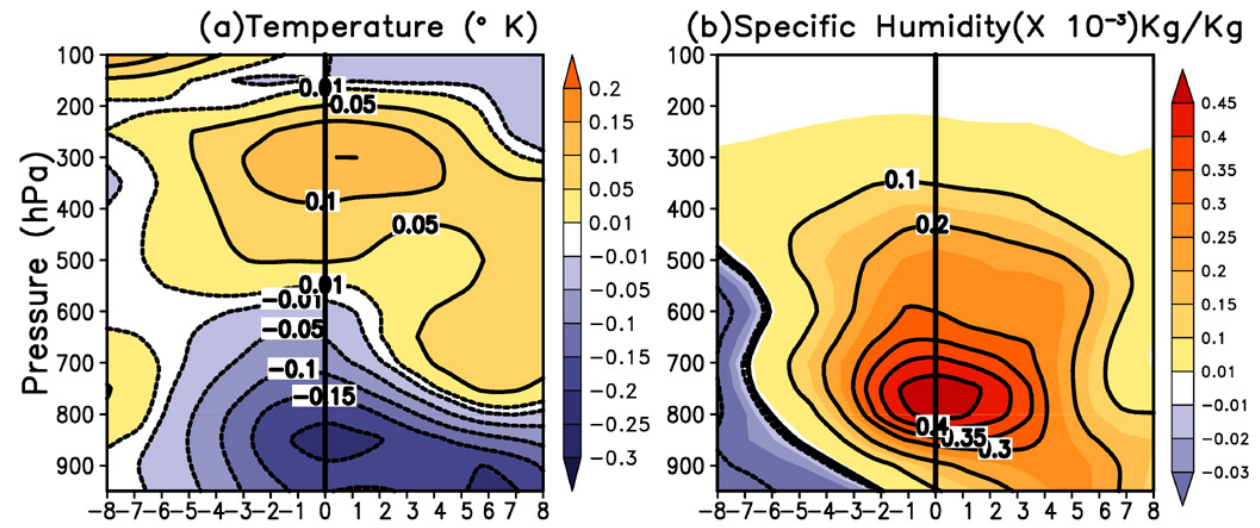

Distance From Convection Center $\left({ }^{\circ}\right)$

Fig. 8. Meridional-vertical structure of (a) temperature $\left({ }^{\circ} \mathrm{K}\right)$ and (b) specific humidity $\left(\mathrm{Kg} \mathrm{Kg}^{-1}\right)$ with respect to convection centre based on MERRA data.

98-08 Active Composite meridional-vertical
structure of anomalous dynamical parameters using MERRA

(a) Moisture Convergence $\left(10^{-8} \mathrm{~s}^{-1}\right)$ (b) Moist Static Energy $(\mathrm{KJ} / \mathrm{Kg})$
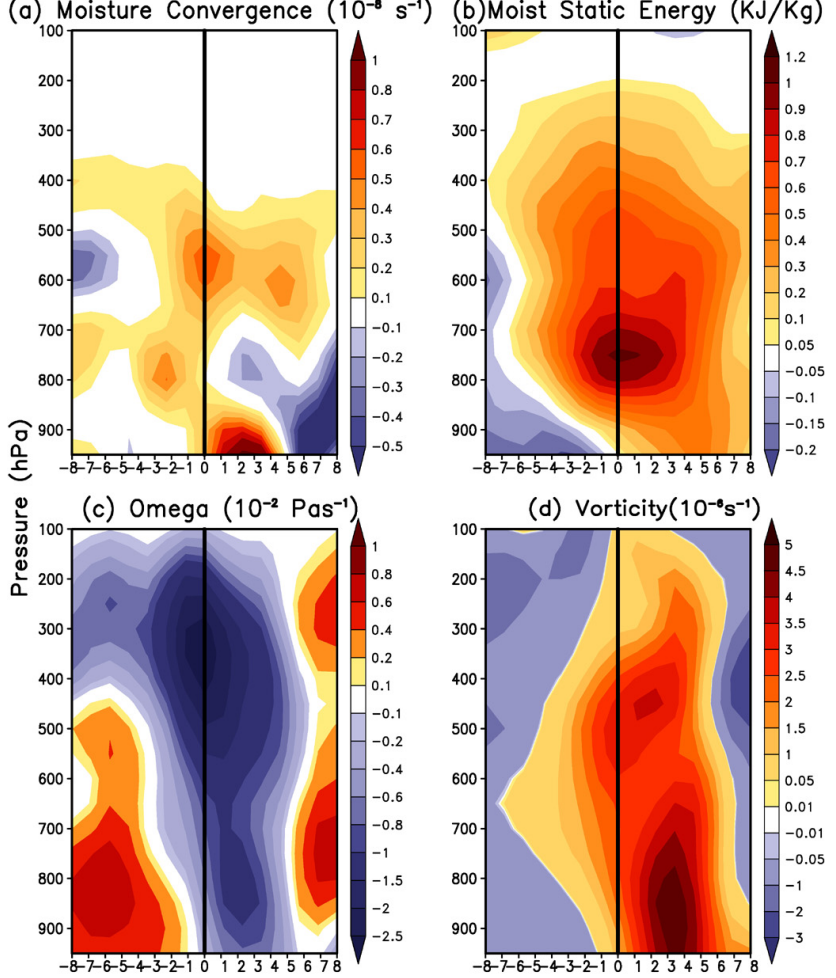

Distance from Convection Center $\left(^{\circ}\right)$

Fig. 9. Meridional-vertical structure of (a) moisture convergence $\left(\mathrm{s}^{-1}\right)$, (b) moist static Energy $\left(\mathrm{KJ} \mathrm{kg}^{-1}\right)$, (c) vertical velocity $\left(\mathrm{Pa} \mathrm{s}^{-1}\right)$ and (d) vorticity $\left(\mathrm{s}^{-1}\right)$ with respect to convection centre based on MERRA data.
Time Latitude Dist of $75 \mathrm{E}-83 \mathrm{E}$ averaged $\mathrm{CLDI}\left(\mathrm{mgm}^{-3}\right.$ day $\left.^{-1}\right)$ and $\operatorname{RF}\left(\mathrm{mmday}^{-1}\right)$ in lag-15 to lag +15 days

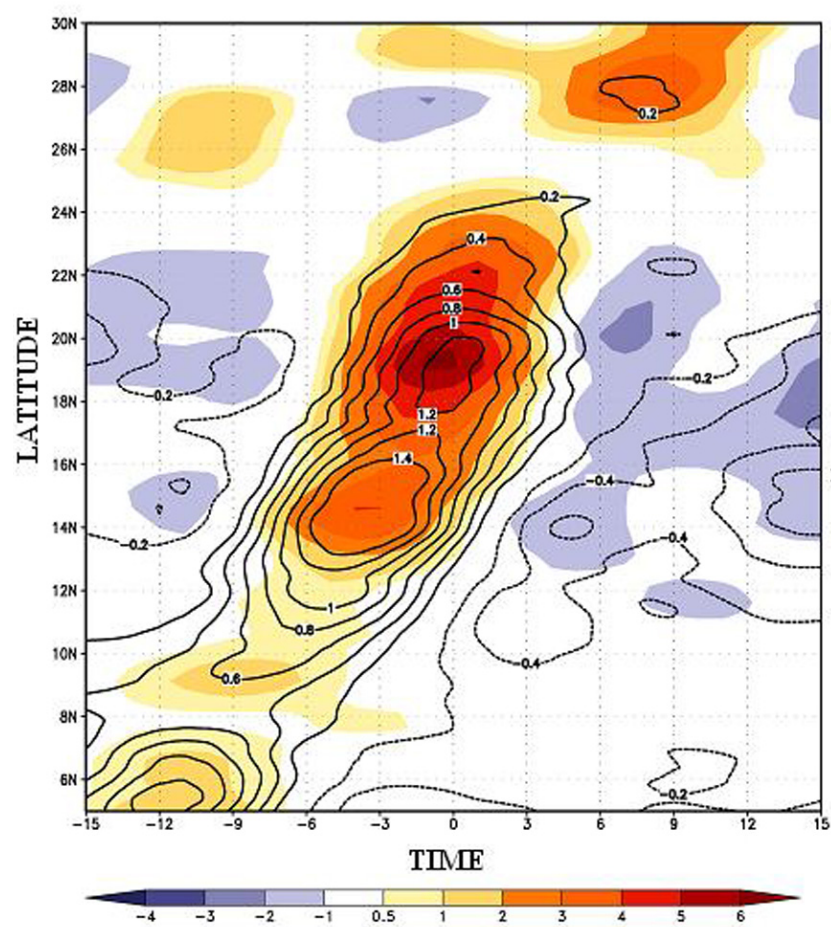

Fig. 10. Hövmöller (Latitude-time) diagram of rainfall $\left(\mathrm{mm} \mathrm{day}^{-1}\right)$ (shaded) superimposed with the cloud ice (contour) $\left(\mathrm{mg} \mathrm{m}^{-3} \mathrm{day}^{-1}\right)$. 
Time Latitude Dist of 75E-83E averaged CLDW $\left(\mathrm{mgm}^{-3} \mathrm{day}^{-1}\right)$ in $\mathrm{RF}\left(\mathrm{mmday}^{-1}\right) \mathrm{lag}-15$ to lag +15 days

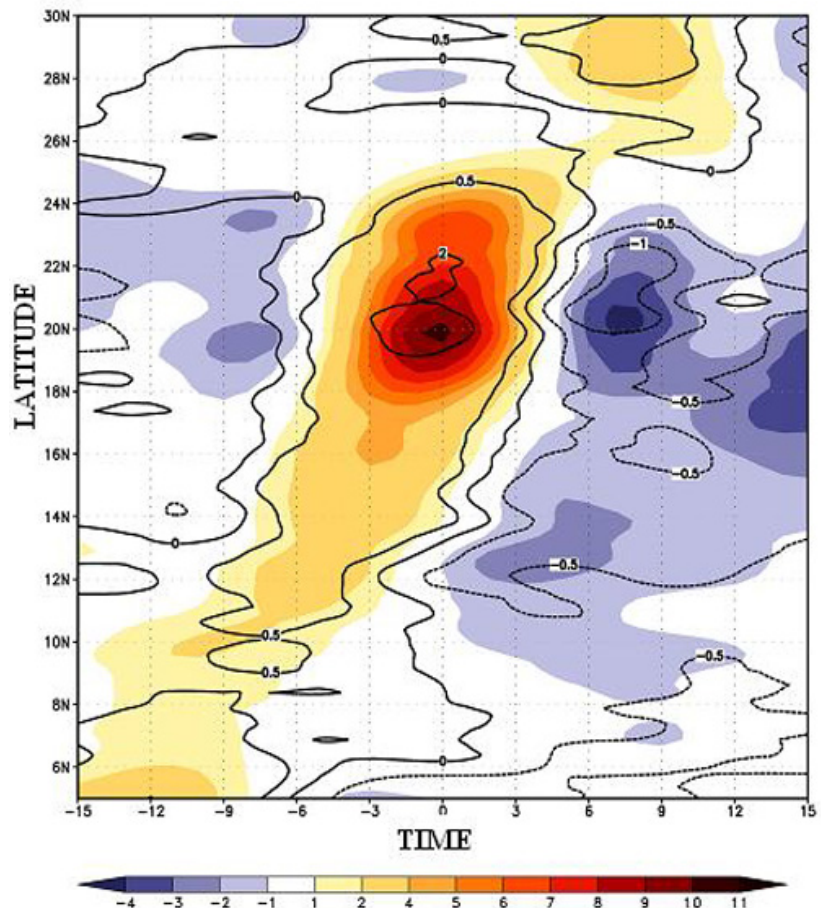

Fig. 11. Hövmöller diagram of rainfall $\left(\mathrm{mm} \mathrm{day}^{-1}\right)$ (shaded) superimposed with the cloud water $\left(\mathrm{mg} \mathrm{m}^{-3} \mathrm{day}^{-1}\right)$ (contour).

equatorial Indian Ocean to the Indian land mass with a periodicity of 30 days similar to what is observed for rainfall. These figures also suggest that the monsoon rainfall shows an organization with three major cloud types, namely low, medium and high cloud. However, these do not throw any light on the relative phases of these hydrometeors with respect to rainfall.

To get an idea about the relative phase of each hydrometeor with respect to 0 lag day of precipitation, a domain averaged $\left(18^{\circ} \mathrm{N}-25^{\circ} \mathrm{N}, 75^{\circ} \mathrm{E}-83^{\circ} \mathrm{E}\right)$ time series of hydrometeors (cloud water and ice) with rainfall is shown in Fig. 7. It is clearly seen that cloud water formation happens prior (leading) to the rainfall maxima and the cloud ice, on the other hand, is lagging with respect to rainfall maxima. These indicate that the lower level shallow convection is initially leading to generation of cloud water. This in turn causes lower level preconditioning of convective instability for deep convection to trigger. The transition from shallow to middle level cloud happens through the formation of mixed phase cloud or precipitable ice, and finally, the formation of anvil occurs subsequently. This is consistent with the results of Jiang et al. (2010) based on Cloudsat and ERA40 data, where he showed that the high clouds with ice phases lag with respect to rainfall maxima followed by the mixed phase and by lower level clouds (predominantly cloud water).

\section{Standard Deviation of $3 \mathrm{G68}$ Stratiform Rainfall mmday 1998-2008}

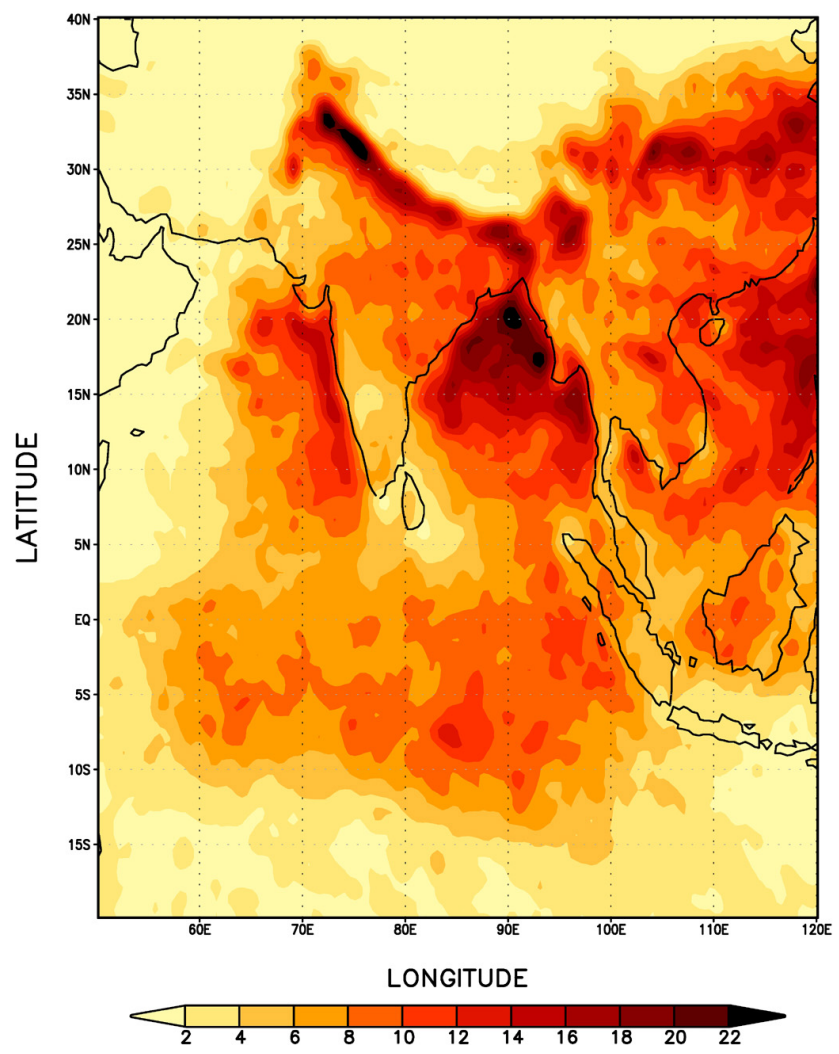

Fig. 12. Standard deviation of JJAS stratiform rainfall $\left(\mathrm{mm} \mathrm{day}^{-1}\right)$ based on 3G68 data from 1998-2008.

To see the associated dynamical parameters during the northward propagation, we analyzed vertical profile of temperature anomaly, vertical velocity, vorticity and anomaly of moist static energy (MSE) as a measure of convective instability. The vertical profile of temperature anomaly indicates lower level cold pool possibly due to evaporation of the hydrometeors and a middle level heating (Fig. 8a). Associated with this we see a lower level maxima in the anomaly of specific humidity (Fig. 8b) and instability (MSE) (Fig. 9b). The growth of lower level instability is initially inhibited by the inversion, which is further passed through the strong lower level moisture convergence (Fig. 9a), vertical velocity (Fig. 9c) and vorticity (Fig. 9d) to the north of the convection centre. The vertical velocity (Fig. 9c) has a southward tilt and the maximum is collocated with convection centre at around $400 \mathrm{hPa}$ level. This finding is consistent with earlier studies, e.g. Jiang et al. (2004).

To see the impact of cloud ice and its phase on the northward propagation of positive rainfall anomaly, a latitude-time Hovmöller diagram is shown in Fig. 10. We find that the cloud ice maximum is lying to the south of the rainfall maxima. Further, to explore the phases between the cloud water 

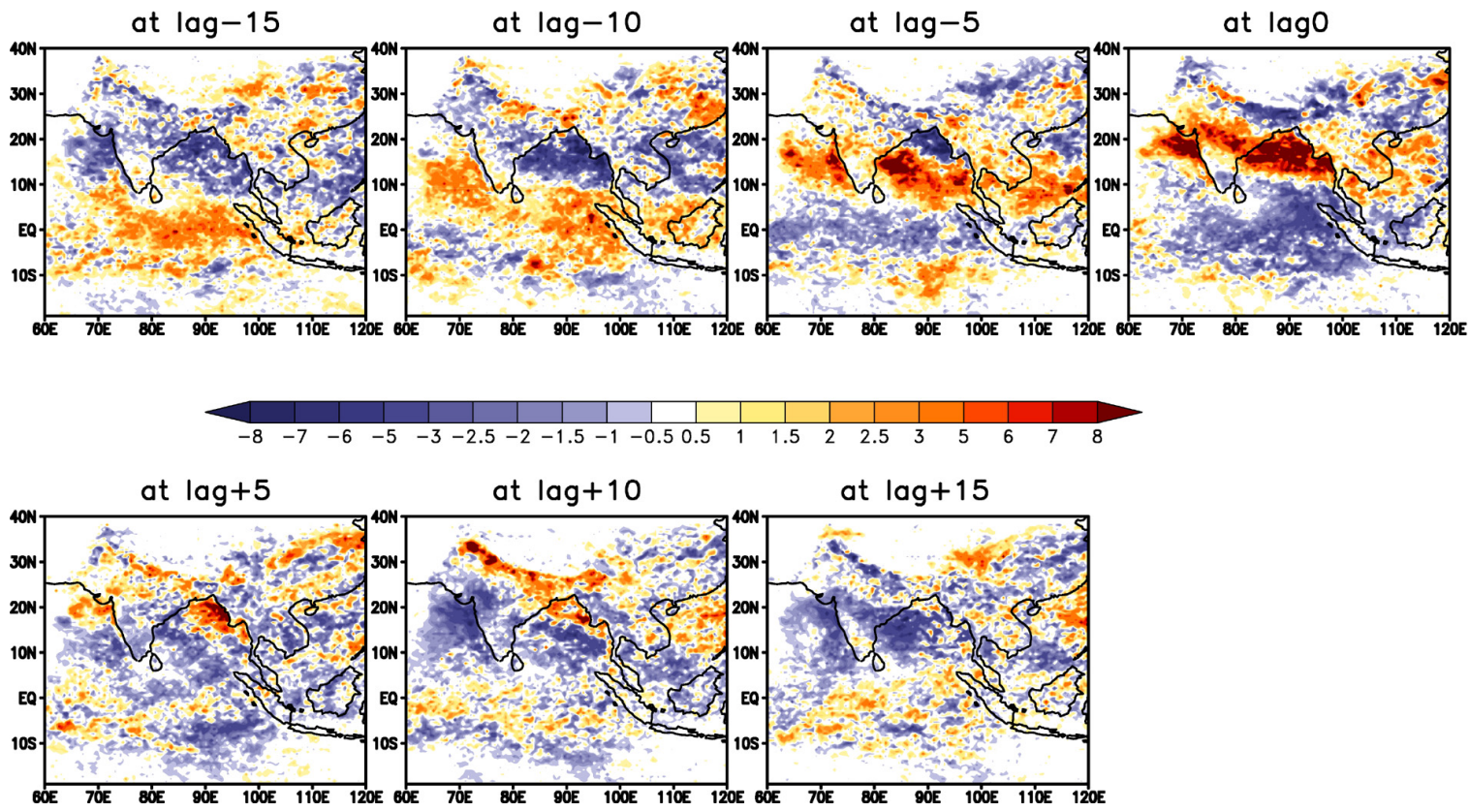

Fig. 13. Lag composite of stratiform rainfall $\left(\mathrm{mm} \mathrm{day}^{-1}\right)$ during active spells based on $3 \mathrm{G} 68$ data.
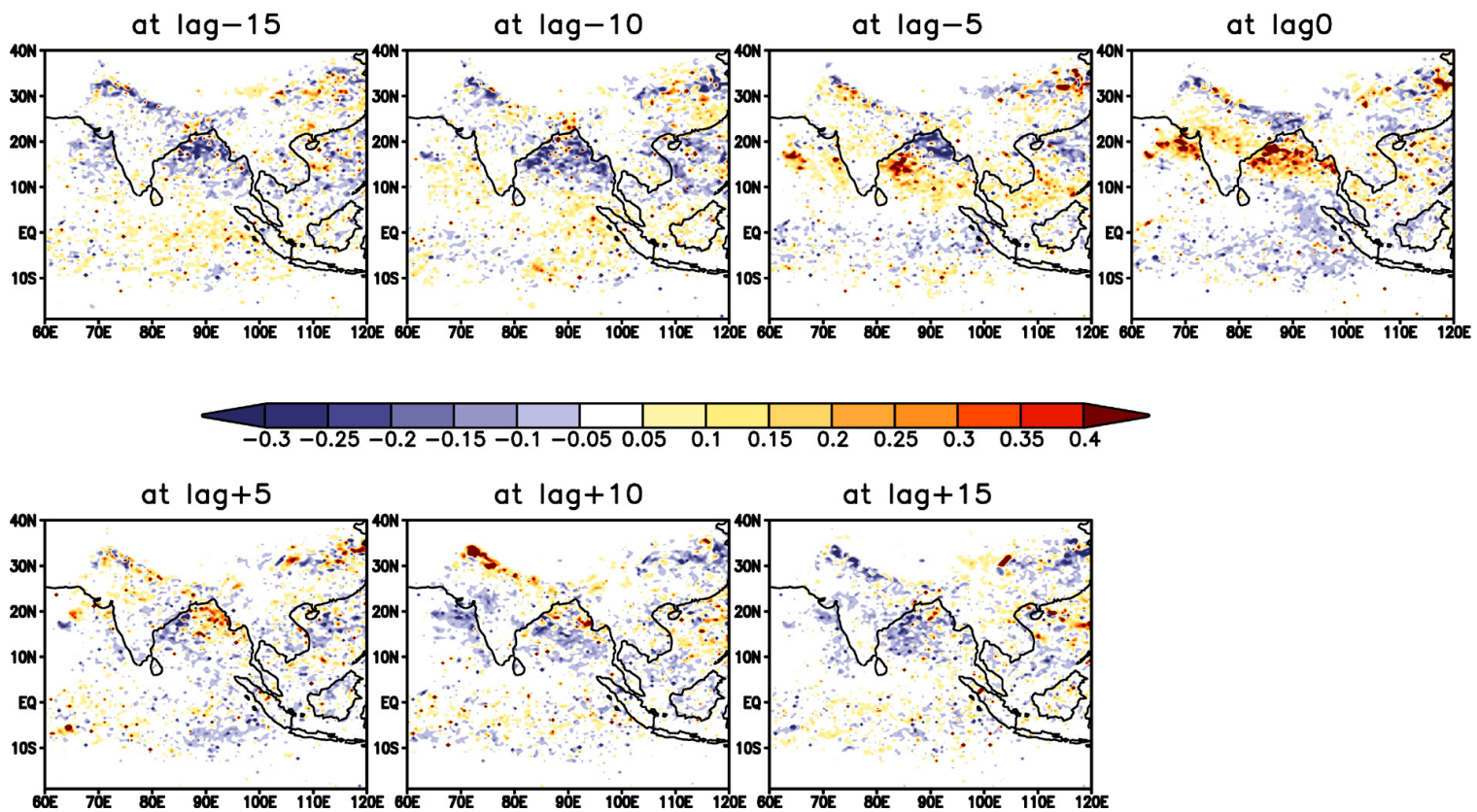

Fig. 14. Lag composite of convective rainfall $\left(\mathrm{mm} \mathrm{day}^{-1}\right)$ during active spells based on TRMM $3 \mathrm{G} 68$ data.

and rain, the Hovmöller diagram of cloud water and rainfall is computed (Fig. 11), which shows that the cloud water maximum is leading (lying to the north) with respect to the rainfall maxima. The above analyses suggest that cloud ice lags the maximum precipitation and the cloud water leads the rainfall. This further establishes the previous conclusion that low level moistening due to moisture convergence and abundance of cloud water preconditions the boundary layer, which subsequently triggers deep convection through strong vertical velocity and vorticity. The cloud ice is formed in the rear associated with the out flow of the deep convection to the south of convection centre.

Many studies (Chattopadhyay et al., 2009) have recently shown that stratiform rainfall actually shows the northward propagation associated with the MISO, and the convective component does not show a prominent northward 
(a) 98-08 Active Composite

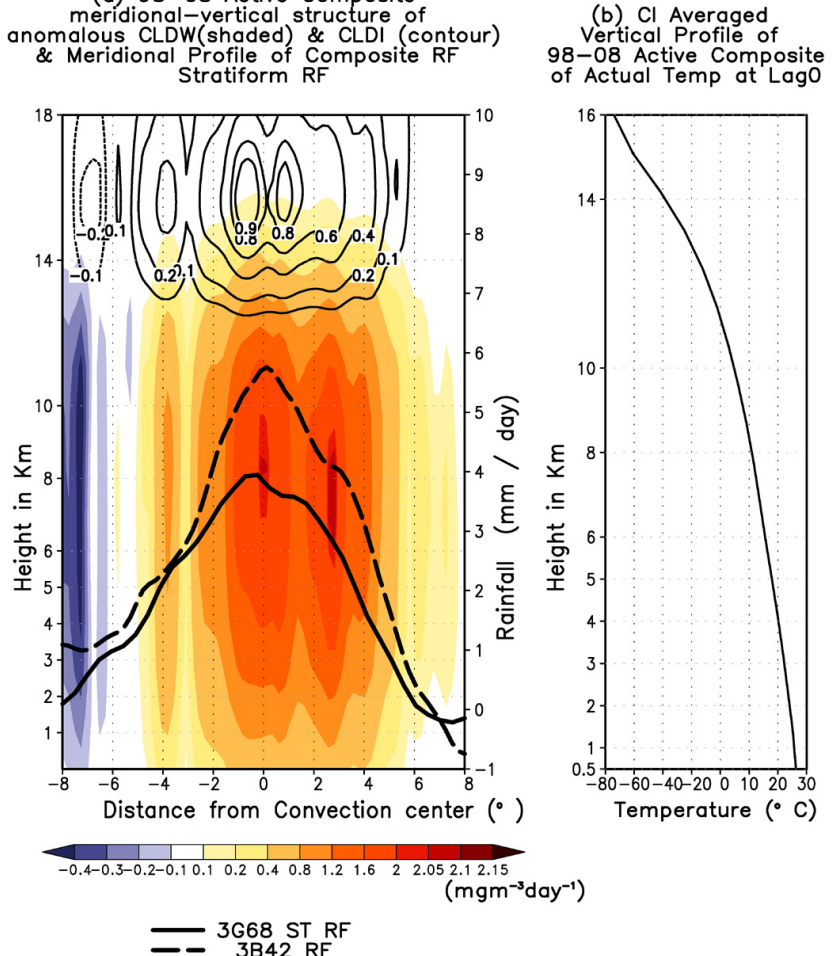

Fig. 15. (a) Domain averaged vertical distribution of cloud water $\left(\mathrm{mg} \mathrm{m}^{-3} \mathrm{day}^{-1}\right)$ (shaded), cloud ice $\left(\mathrm{mg} \mathrm{m}^{-3} \mathrm{day}^{-1}\right)$ (contour) with respect to convection centre superimposed with total rainfall $\left(\mathrm{mm} \mathrm{day}^{-1}\right)$ (solid line) and stratiform rainfall $\left(\mathrm{mm} \mathrm{day}^{-1}\right)$ (broken line), (b) domain averaged vertical profile of temperature $\left({ }^{\circ} \mathrm{C}\right)$ at lag 0 .

propagation. Houze Jr. (1982) has suggested that the stratiform rain is a manifestation of high clouds or ice phase. It is also well documented (Houze Jr., 1982) that the old convection generates the anvil, which is mostly comprised of ice phase, and these persisting anvils interact with the large scale environment and modulate the heating distribution of the atmosphere (Baker, 1997). The stratiform rain is a manifestation of these persisting ice phase anvils which has a dominant influence on radiation and heat budget of the atmosphere, and subsequently to circulation. An important point is that convection is rather short-lived $(\leq 1 \mathrm{~h})$ and sporadic, while stratiform rain is more widespread and long lived.

Keeping this in background, we want to explore the role of ice phase with the startiform and convective component of total rainfall using TRMM 3G68 data. The standard deviation (SD) of the stratiform component (Fig. 12) of rainfall from the TRMM 3G68 data resembles the regional feature shown by the total rainfall (Fig. 2), indicating the dominant contribution of the stratiform rain in the total rainfall variance. We have also analyzed (figure not shown) the SD of the convective rainfall to see the variability in the convective component. It is found that SD of convective rainfall does not

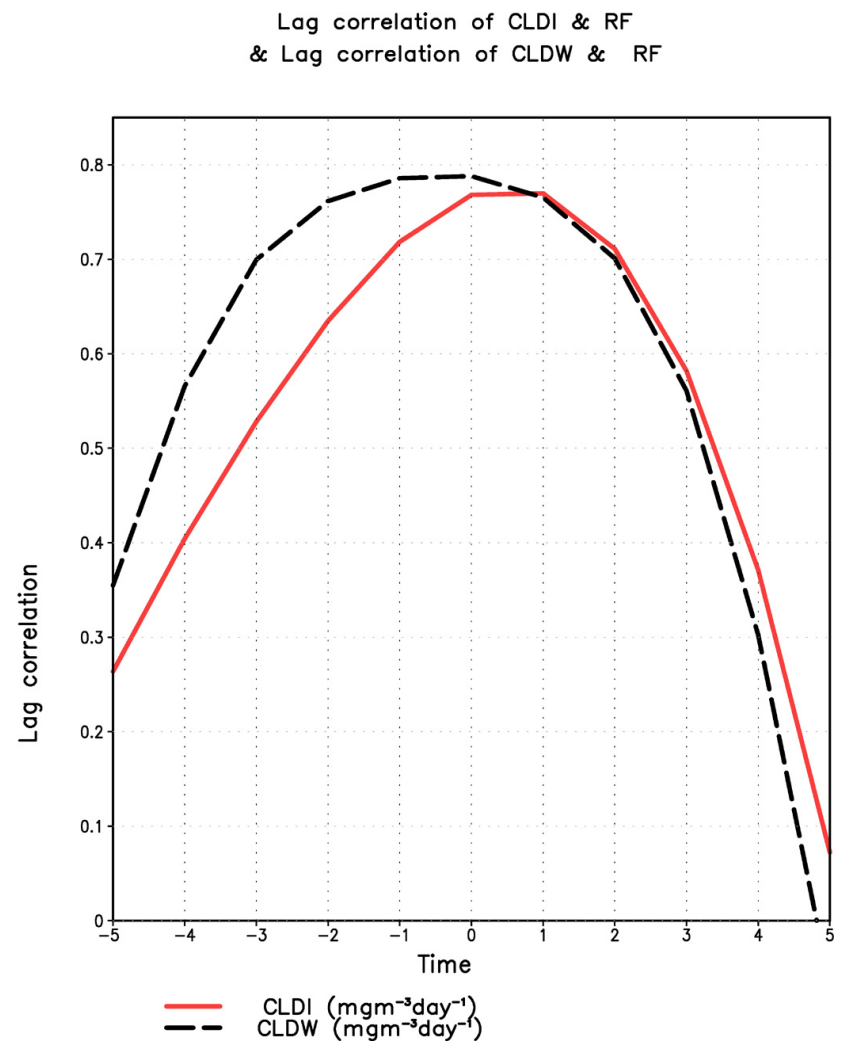

Fig. 16. Domain averaged lag correlation of cloud water (CLDW) and cloud ice (CLDI) with respect to rainfall.

show noticeable variability as compared to what is observed from the total rainfall (Fig. 2). The SD of convective rainfall fails to show the spatial variability over hills and central plains over the Indian region.

Based on this, we analyzed the TRMM 3 G68 stratiform rainfall component and computed a lag-lead composite of active spells (Fig. 13). It is found that the stratiform rainfall $\left(\mathrm{mm} \mathrm{day}^{-1}\right)$ has a well defined large scale organization and a steady northward propagation starting from the equatorial Indian Ocean at lag -15 days. However, a similar plot of convective rainfall $\left(\mathrm{mm} \mathrm{day}^{-1}\right)$ (Fig. 14) hardly shows any northward propagation in consistence with earlier studies (Chattopadhyay et al., 2009). The fact that (relatively short-lived) deep convective clouds generally cover a much smaller area than the (longer-lived) stratiform anvils could explain such a situation, where "convective rainfall hardly shows any northward propagation in consistence with earlier studies (Chattopadhyay et al., 2009)".

To study the phases between the total rain, stratiform rain, cloud ice and cloud water, a domain averaged vertical section of cloud ice and cloud water superimposed by rainfall are shown in Fig. 15a. The figure clearly brings out that the cloud water leads the total rainfall, although one of its maxima is collocated with the convection centre. This maximum could be attributed to the convective core. A similar 


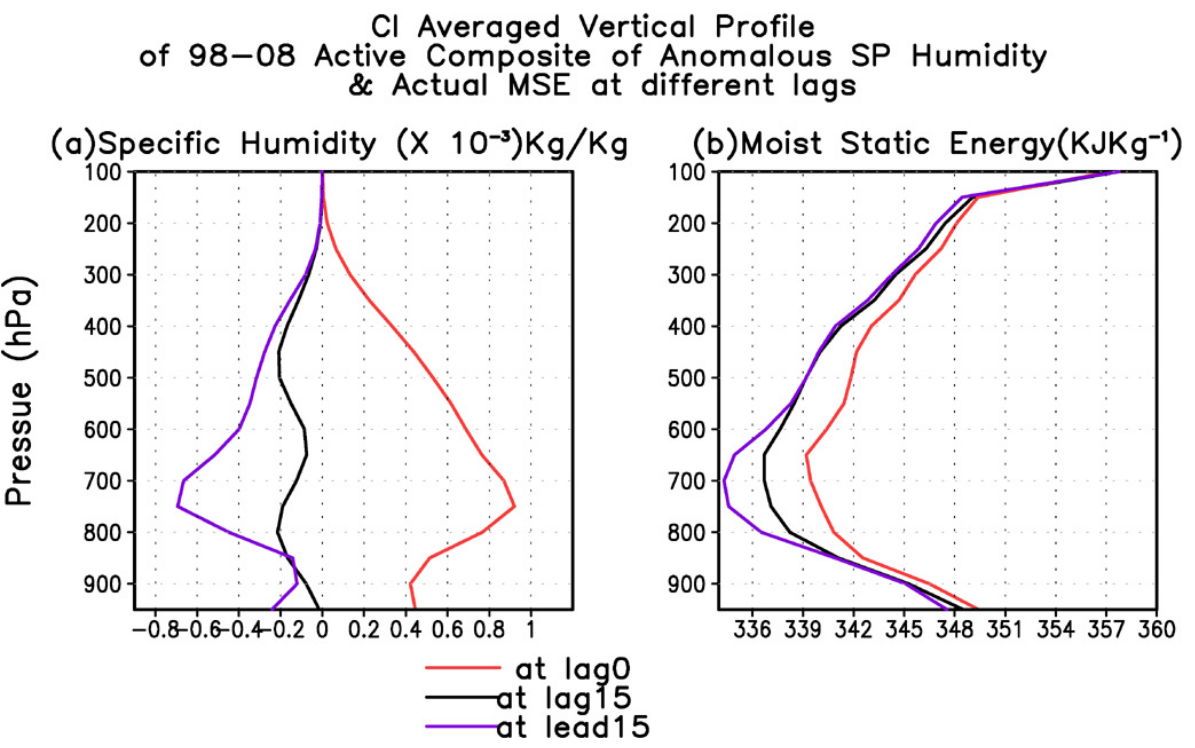

Fig. 17. Central India averaged vertical profile of (a) specific humidity $\left(\mathrm{Kg} \mathrm{kg}^{-1}\right)$ and (b) moist static energy $\left(\mathrm{KJ} \mathrm{kg}^{-1}\right)$ for lag -15 , lag 0 and lead 15 based on MERRA.

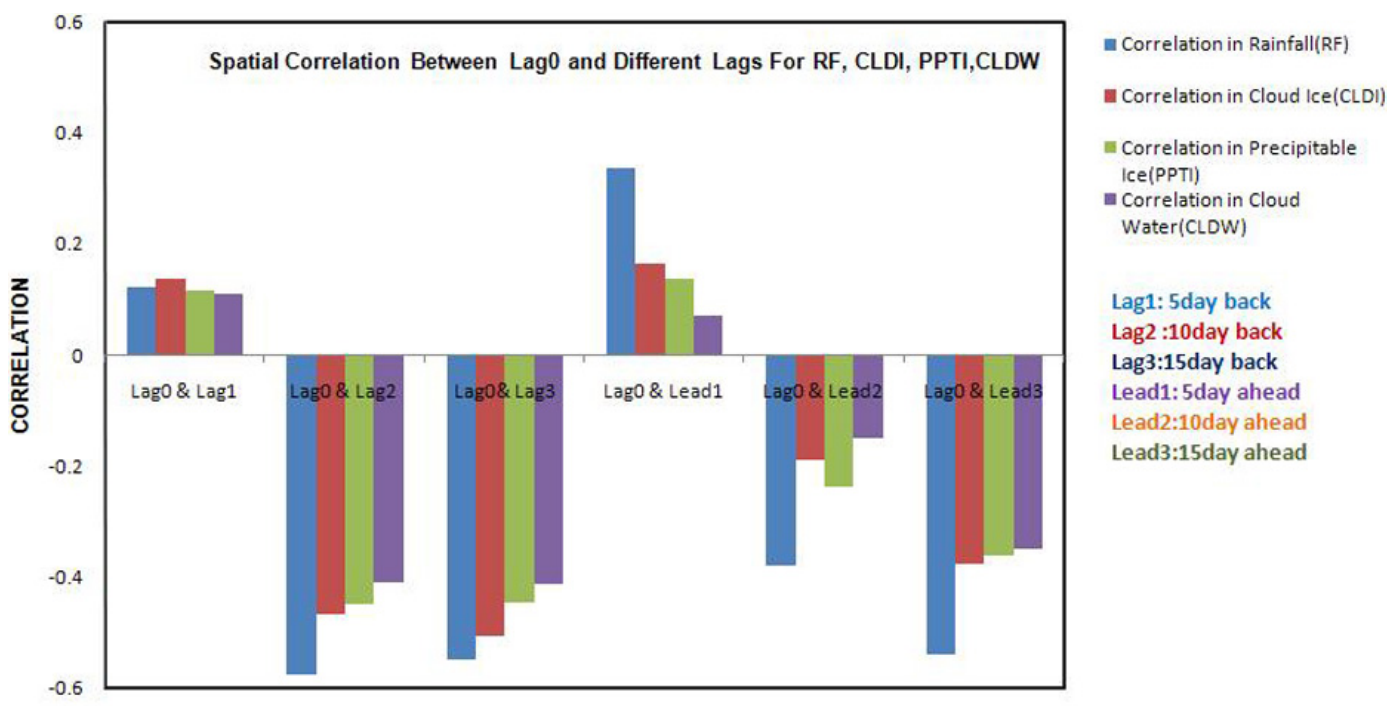
Variance Explained by RF Anomaly in different Lags
$1.5 \%, 33 \%, 30 \%, 11.4 \%, 14.4 \%, 29.2 \%$

Variance Explained by PPTIAnomaly in different Lags $1.3 \%, 20.5 \%, 20 \%, 2 \%, 6 \%, 13.3 \%$
Variance Explained by CLDI Anomaly in different Lags $1.88 \%, 21.75 \%, 25.7 \%, 2.7 \%, 3.5 \%, 14.12 \%$

Variance Explained by CLDW Anomaly in different Lags $1.1 \%, 16.7 \%, 17.1 \%, 0.63 \%, 2.3 \%, 13 \%$

Fig. 18. Spatial correlation between lag 0 and lag 1, lag 2, lag 3, lead 1, lead 2 and lead 3 for each hydrometeor type and rainfall and corresponding variance explained using TRMM data.

cloud water distribution is reported by Jiang et al. (2010). The cloud ice is found to be lagging with respect to convection centre and the stratiform rain maxima is collocated with the cloud ice maxima. The corresponding temperature profile is shown in Fig. 15b, which reveals that super cooled cloud liquid water is prevalent even at $-30^{\circ}$ to $-40^{\circ} \mathrm{C}$, consistent with the recent study of $\mathrm{Hu}$ et al. (2010). To objectively quantify the phase relation of cloud ice (CLDI) and cloud water (CLDW) with rainfall, the lag correlation is computed with rainfall. The domain averaged lag correlation with respect to 
convection center is shown in Fig. 16. The lag correlation clearly shows the relative phase of the CLDI as lagging and CLDW as leading with respect to convection center during northward propagation of MISO.

The above analyses bring out the fact that the northward propagation of positive rainfall anomaly is associated with distinct hydrometeor distribution. The lower level moistening and preconditioning of atmosphere happens through the initial built up of instability inhibited by inversion which is passed through the boundary layer convergence that triggers deep convection. Deep convective cloud detrain a lot of cloud droplets and small ice crystals in the upper troposphere. The slow cold microphysical processes, combined with weak latent heat release and alleviated water loading as precipitation fall out, explain the longer duration (few hours or more) of trailing stratiform anvils compared to the relatively shortlived (less than $1 \mathrm{~h}$ ) deep convective clouds. A possible impact of a stratiform anvil on propagation is through the formation of a low-level cold pool through evaporation of hydrometeors in a dry mid-level rear inflow (Fig. 8b). It is also found from the vertical profile of specific humidity (Fig. 17a) and MSE (Fig. 17b) at different lag that the lower level moisture and instability steadily increases from -15 lag onwards. Subsequently, the energy is released on 0 lag and again starts building up through following days (lead 15).

The variance explained by different hydrometeors and rainfall are also demonstrated through the correlation of lag composite (Fig. 18). The spatial correlation with lag 0 and lag 1 or between lag 0 and lead 1 is not very high, whereas that between lag 0 and lag 2 or lag 0 and lag 3, and similarly with lead 2 and lead 3 is very high. Variance of around $15-30 \%$ is explained by these lag composite (lag 0-lag 2, lag 0-lag 3, lag 0-lead 2, lag 0-lead 3) for each hydrometeor and rainfall. These analyses indicate that more variance is explained by 10 day or 15 day lagged (lead) composites of hydrometeors or rain, and comparatively lesser variance is explained with 5 day or 0 day lagged (lead) composites of hydrometeors and rain. The fact that more variance is explained by 10- to 15-day lagged composites and less by 5 to 0 -day variance could result from a relatively well-defined synoptic scale envelope, within which meso- and small scale convective systems develop sporadically.

\section{Conclusion}

An attempt is made here to identify the role of cloud hydrometeors and their linkage with the MISO. Although MISO phases and its propagation are much studied with the help of a suite of rainfall data, the role of hydrometeors phases has hardly been explored. It is found from the Hovmöller plots and lag composite analyses that the cloud liquid water formation happens prior to the rainfall maxima. Analyses of dynamical parameters reveal that convective instability builds up in the boundary layer due to low level moisture convergence and enhanced moist static energy to the north of convection center. This essentially works in preconditioning the convective instability for deep convection to trigger. Subsequently, through the barotropic vertical velocity and vorticity, deep convection is triggered to the north of the convection center. The formation of cloud liquid water maximum in the lower level results in the release of latent heating which further facilitates the instability to the north of convection center. The mixed phase hydrometeors are in phase with the rainfall, whereas the cloud ice lags the rainfall maxima. The relation between cloud ice, cloud water, total rainfall and stratiform rainfall establishes the fact that the stratiform component of the total rain is collocated with cloud ice maxima. These results are consistent with many earlier results but TRMM 2A12 data is first time utilized here in the context of MISO. As seen from the analyses, the stratiform rain shows a significant northward progression, but convective rain hardly shows any coherent northward propagation. We also bring out in the study the relation of different cloud hydrometeor and their role in relation to MISO northward propagation. The lag correlation plot clearly demonstrates that cloud water leads the rainfall maxima and cloud ice lags. As the MISO and its propagation characteristics still remain a challenge for numerical models, particularly GCMs, we feel, this study demonstrates the need of incorporating these processes in climate models to better simulate the characteristics of MISO of ISM.

Acknowledgements. Madhuparna Halder acknowledges the Council of Scientific and Industrial Research, Govt. of India, for financial support. IITM is fully funded by Ministry of Earth science, Government of India. Authors gratefully acknowledge B. N. Goswami, Director, IITM for suggestions and encouragement on the study. Authors thank Robert A. Houze Jr. of Department of Atmospheric Sciences, University of Washington and Chris Kummerow of Department of Atmospheric Sciences, Colorado State University, USA, and R. H. Kripalani, IITM, Pune for their valuable suggestions and discussions. Authors thank anonymous reviewers for constructive comments. Authors thankfully acknowledge Goddard Earth Sciences (GES) Data and Information Services Centres (DISC), NASA for MERRA reanalyses and GSFC, NASA for TRMM data.

Topical Editor P. M. Ruti thanks two anonymous referees for their help in evaluating this paper.

\section{References}

Baker, M. B.: Cloud microphysics and climate, Science, 276, 10721078, 1997.

Bony, S., Dufresne, J.-L., Treut, H. Le., Morerte, J. J., and Senior, C.: On dynamic and thermodynamic components of cloud changes, Clim. Dynam., 22, 71-86, doi:10.1007/S00382-0030369-6, 2004.

Chattopadhyay, R., Goswami, B. N., Sahai, A. K., and Fraedrich, $\mathrm{K}$.: Role of stratiform rainfall in modifying the northward propagation of monsoon intraseasonal oscillation, J. Geophys. Res., 114, D19114, doi:10.1029/2009JD011869, 2009. 
Duchon, C. E.: Lanczos filtering in one and two dimensions, J. Appl. Meteorol., 18, 1016-1022, 1979.

Fu, X., Wang, B., Li, T., and McCreary, J. P.: Coupling between northward-propagating, intraseasonal oscillations and sea surface temperature in the Indian Ocean, J. Atmos. Sci., 60, 17331753, 2003.

Goswami, B. N.: South Asian monsoon, in: Intraseasonal Variability of the Atmosphere-Ocean Climate System, edited by: Lau, W. K. M. and Waliser, D. E., Springer, Berlin, 19-61, 2005.

Goswami, B. N., Wu. G., and Yasunari, T.: Annual cycle, Intraseasonal Oscillations and Roadblock to seasonal predictability of the Asian summer monsoon, J. Climate, 19, 5078-5099, 2006.

Haddad, Z. S., Short, D. A., Durden, S. L., Hensley, E. Im. S., Grable, M. B., and Black, R. A.: A new parameterization of the rain drop size distribution, IEEE Trans. Geosci. Remote Sens., 35, 532-539, doi:10.1109/36.581961, 1997a.

Haddad, Z. S., Smith, E. A., Kummerow, C., Iguchi, T, Farrar, M. R., Durden, S. L., Alves M., and Olson, W. S.: The TRMM 'day1' radar/radiometer combined rain-profiling algorithm, J. Meteorol. Soc. Jap., 75, 799-809, 1997b.

Houze Jr., R. A.: Cloud clusters and large-scale vertical motions in the tropics, J. Meteorol. Soc. Jap., 60, 396-410, 1982.

Houze Jr., R. A.: Stratiform precipitation in regions of convection: A meteorological paradox?, B. Am. Meteorol. Soc., 78, 21792196, 1997.

Hoyos, C. D. and Webster, P. J.: The role of intraseasonal variability in the nature of Asian monsoon precipitation, J. Climate, 20, 4402-4424, 2007.

Hsu, H.-H. and Weng, C.-H.: Northwestward propagation of the intraseasonal oscillation in the western North Pacific during the boreal summer: Structure and mechanism, J. Climate, 14, 38343850, 2001.

Hu, Y., Rodier, S., Xu, K.-M., Sun, W., Huang, J., Lin, B., Zhai, P., and Josset, D.: Occurrence, liquid water content, and fraction of supercooled water clouds from combined CALIOP/IIR/MODIS measurements, J. Geophys. Res., 115, D00H34, doi:10.1029/2009JD012384, 2010.

Huffman, G. J.: The global precipitation climatology project (GPCP) combined precipitation dataset, B. Am. Meteorol. Soc., 78, 5-20, 1997.

Huffman, G. J., Adler, R. F., Rudolf, B., Schneider, U., and Keehn, P. R.: Global precipitation estimates based on a technique for combining satellite-based estimates, rain gauge analysis, and NWP model precipitation information, J. Climate, 8, 1284-1295, 1995.

Iguchi, T., Kozu, T., Meneghini, R., Awaka, J., and Okamoto, K.: Rain-Profiling Algorithm for the TRMM Precipitation Radar, J. Appl. Meteorol., 39, 2038-2052, doi:10.1175/15200450(2001)040;2038:RPAFTT $i 2.0 . C O ; 2,2000$.

Jiang, X., Li, T., and Wang, B.: Structures and mechanisms of the northward propagating boreal summer intraseasonal oscillation, J. Climate, 17, 1022-1039, 2004.

Jiang, X., Waliser, D. E., and Li, J.: Vertical cloud structures of the boreal summer intraseasonal variability based on CloudSat observations and ERA-interim reanalysis, Clim. Dynam., 36, 22192232, doi:10.1007/s00382-010-0853-8,2010.

Johnson, R. H.: Partitioning tropical heat and moisture budgets into cumulus and 22 mesoscale components: Implications for cumulus parameterization, Mon. Weather Rev., 112, 1590-1601, 1984.
Kemball-Cook, S. and Wang, B.: Equatorial waves and air-sea interaction in the boreal summer intraseasonal oscillation, J. Climate, 14, 2923-2942, 2001

Krishna Kumar, K., Kamala, K., Rajagopalan, B., Hoerling, M. P., Eischeid, J. K., Patwardhan, S. K., Srinivasan, G., Goswami, B. N., and Nemanai, R.: The once and future pulse of Indian monsoonal climate, Clim. Dynam., 36, 2159-2170, doi:10.1007/s00382-010-0974-0, 2011.

Kummerow, C., Hong, Y., Olson, W. S., Yang, S., Adler, R. F., McCollum, J., Ferraro, R., Petty, G., Shin, D-B., and Wilheit, T. T.: The evolution of the Goddard profiling algorithm (GPROF) for rainfall estimation from passive microwave sensors, J. Appl. Meteorol., 40, 1801-1820, doi:10.1175/15200450(2001)040<1801:TEOTGP > 2.0.CO:2, 2001.

Lau, W. K. M. and Waliser, D. E.: Intraseasonal Variability of the Atmosphere-Ocean Climate System, Springer, Germany, 474 pp., 2005.

Lawrence, D. M. and Webster, P. J.: The boreal summer intraseasonal oscillation: Relationship between northward and eastward movement of convection, J. Atmos. Sci., 59, 1593-1606, 2002.

L'Ecuyer, T. S. and McGarragh, G.: A 10-year climatology of Tropical radiative Heating and Its Vertical Structure from TRMM Observations, J. Climate, 23, 3, doi:10.1175/2009JCL13018.1, Special TRMM Diabatic Heating Collection, 2010.

Madden, R. A. and Julian, P. R.: Observations of the 40-50 day tropical oscillation - A review, Mon. Weather Rev., 122, 814837, 1994.

Pattanaik, D. R. and Kumar, A.: Prediction of summer monsoon rainfall over India using the NCEP climate forecast system, Clim. Dynam., 34, 557-572, doi:10.1007/s0.0382-009-0648-y, 2010.

Schumacher, C. and Houze Jr., R. A.: Stratiform rain in the tropics as seen by the TRMM precipitation Radar, J. Climate, 16, 17391756, 2003.

Shankar, D., Shetye, S. R., and Joseph, P. V.: Link between convection and meridional gradient of sea surface temperature in the Bay Of Bengal, J. Earth Syst. Sci., 116, 385-406, 2007.

Sikka, D. R. and Gadgil, S.: On the maximum cloud zone and the ITCZ over Indian longitudes during the southwest monsoon, Mon. Weather Rev., 108, 1840-1853, 1980.

Sperber, K. R., Slingo, J. M., and Annamalai, H.: Predictability and the relationship between subseasonal and interannual variability during the Asian Summer Monsoon, Q. J. Roy. Meteorol. Soc., 126, 2545-2574, 2000.

Waliser, D. E.: Intraseasonal Variations, The Asian Monsoon, edited by: Wang, B., Springer, Heidelberg, Germany, 787, 2006.

Waliser, D. E., Jin, K., Kang, I.-S., Stern, W. F., Schubert, S. D., Wu, M. L. C., Lau, K. M., Lee, M. I., Krishnamurthy, V., Kitoh, A., Meehl, G. A., Galin, V. Y., Satyan, V., Mandke, S. K., Wu, G., Liu, Y., and Park, C. K.: AGCM simulations of intraseasonal variability associated with the Asian Summer Monsoon, Clim. Dynam., 21, 423-446, 2003

Wang, B. and Xie, X.: A model for the boreal summer intraseasonal oscillation, J. Atmos. Sci., 54, 72-86, 1997.

Wang, B., Webster, P. J., and Teng, H.: Anteceedents and selfinduction of active-break south Asian monsoon unraveled by satellites, Geophys. Res. Lett., 32, L04704, doi:10.1029/2004GL020996, 2005.

Webster, P. J.: Mechanisms of low-frequency variability: Surface hydrological effects, J. Atmos. Sci., 40, 2110-2124, 1983. 
Wylie, D. P., Menzel, W. P., and Strabala, K. I.: Four years of global cirrus cloud statistics using HIRS, J. Climate, 7, 1972-1986, 1994.

Yasunari, T.: Cloudiness fluctuation associated with the Northern Hemisphere summer monsoon, J. Meteorol. Soc. Jap., 57, $227-$ 242, 1979.

Yuan, J. and Hartmann, D. L.: Spatial and Temporal dependence of clouds and their radiative impacts on the large scale vertical velocity profile, J. Geophys. Res., 113, D19201, doi:10.1029/2007JD009722, 2008.
Zhang, C.: The Madden-Julian Oscillation, Rev. Geophys., 43, RG2003, doi:10.1029/2004RG000158, 2005.

Zuluaga, M. D., Hoyos, C. D., and Webster, P. J.: Spatial and Temporal Distribution of Latent Heating in the South Asian Monsoon Region, J. Climate, 23, 2010-2029, 2010. 